\title{
Alpha-1 Antitrypsin Blood Levels as Indicator for the Efficacy of Cancer Treatment
}

\author{
Zeyad J. El-Akawia, d, Aymen M. Abu-awad ${ }^{b}$, Nabil A. Khouric
}

\begin{abstract}
Background: Alpha- 1 antitrypsin $\left(\alpha_{1}-\mathrm{AT}\right)$ is a member of the serine protease inhibitors (serpins) family. Liver cells are the major source of synthesis and secretion of $\left(\alpha_{1}-\mathrm{AT}\right)$ into the blood. Moreover, it has been demonstrated that $\alpha_{1}$-AT is expressed and secreted by many types of malignant cells. Studies have indicated that serum levels of $\left(\alpha_{1}-\mathrm{AT}\right)$ increase in a good number of malignant diseases. In addition, a significant correlation between serum levels and cancer stage has also been reported. In this work we aimed to test how $\alpha_{1}$-AT levels behave at the third week after treatment with chemotherapy.
\end{abstract}

Methods: The $\alpha_{1}$-AT blood levels were measured using commercially available radial immunodiffusion kit (Kent Laboratory Inc, Bellinham, Washigton) following manufacturer instructions.

Results: The $\alpha_{1}$-AT blood levels were significantly decreased after treatment compared with those before the treatment started. The mean difference (before - after) treatment was 127.82 and 137.37 $\mathrm{mg} / \mathrm{dL}$ with $95 \% \mathrm{CI}$ of difference 109.06 - 146.57 and 116.08 $158.65 \mathrm{mg} / \mathrm{dL}$ in lung and prostate cancer respectively. When we compared these levels according to the stage of cancer, we found that the mean difference (before - after) treatment was also highly significant as indicated by P-value and the $95 \%$ CI of these differences.

Conclusions: Obtained data strongly indicate the value of testing $\alpha_{1}$-AT blood levels as one of the important indicators for the efficacy of cancer treatment.

\footnotetext{
Manuscript accepted for publication April 26, 2013

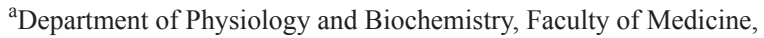
Jordan University of Science and Technology, Irbid 22110, Jordan

${ }^{b}$ Princess Iman Center of Research and Laboratory Sciences, King Hussein Medical Center, Royal Medical Services, Amman, Jordan ${ }^{c}$ Department of Anatomy, Faculty of Medicine, Jordan University of Science and Technology, Irbid 22110, Jordan

${ }^{\mathrm{d} C}$ Corresponding author: Zeyad J. El-Akawi, Biochemistry and Molecular Biology, Faculty of Medicine/Jordan University of Science and Technology, Irbid 22110, Jordan. Email: zakawi@just.edu.jo
}

doi: http://dx.doi.org/10.4021/wjon663e
Keywords: Alpha-1 antitrypsin, Cancer; Treatment

\section{Introduction}

Alpha-1 antitrypsin $\left(\alpha_{1}-\mathrm{AT}\right)$ is a serum glycoprotein which synthesized mainly in human liver cells and macrophages. It is one of a serpins family which plays a central role in controlling tissue degradation through its inhibitory effect on neutrophile elastase and other serine proteases including; trypsin, chymotrypsin, cathepsin G, plasmin, thrombin, tissue kallikrein and activated factor X (FXa). These proteins constitute the third major protein component of blood plasma after albumin and the immunoglobulins [1-3]. It was demonstrated that many types of tumor cells are capable of expression and secretion of $\alpha_{1}$-AT [4-6]. In addition, It has been shown that $\alpha_{1}$-AT serum levels get elevated in a number of inflammatory diseases and different types of malignancies such as hepatocellular carcinoma, multiple myeloma, pancreatic carcinoma, prostatic carcinoma, primary carcinoma of the lung, cervical carcinoma, gastric cancer, laryngeal carcinoma, nasopharyngeal carcinoma, breast cancer and colorectal carcinoma [7-13]. These elevated levels were found to be correlated with the cancer staging as demonstrated in a good number of investigations [8, 14-17]. Considering the above facts concerning $\alpha_{1}$-AT and its relation to cancer, we decided to test how $\alpha_{1}$-AT blood levels behave during cancer treatment with chemotherapy and the correlation between the change in these levels and the treatment outcome.

\section{Material and Methods}

In order to test for how $\alpha_{1}$-AT blood levels behave during the course of cancer treatment with chemotherapy, one hundred newly diagnosed untreated male cancer patients who are admitted to King Hussein Medical Center (K.H.M.C.) and Albashir Hospital in Amman were included in this study. The group of selected patients was consisting of fifty patients, mean age was $54(35-70)$ years, with non-small cell lung 
Table 1. Mean Difference (Before - After) Treatment of Alpha-1 Antitrypsin Blood Levels in mg/ $\mathrm{dL}$ in Lung and Prostate Cancer Patients

\section{Lung cancer Prostate cancer}

$\begin{array}{lll}\text { Number of patients } & 50 & 50 \\ \text { Mean difference (before - after) treatment } & 127.82 & 137.37 \\ \text { SE (mean difference) } & 9.33 & 10.59 \\ \text { 95\% CI of difference } & 109.06,146.57 & 116.08,158.65 \\ \text { P-value using paired (t) test } & 0.000 & 0.000\end{array}$

SE: Standard Error; CI: Coefficient Interval.

cancer and the other fifty patients, mean age was $61(50-70)$ years, with prostate cancer. Non-small cell lung cancer patients were classified based on the stage of the disease with the following distribution: 13 patients with stage I, 14 patients with stage II, 14 patients with stage III, and 9 patients with stage IV. The other fifty patients with prostate cancer were distributed based on the cancer staging as follows: 11 patients with stage A, 13 patients with stage $B, 12$ patients with stage $\mathrm{C}$ and 14 patients with stage $\mathrm{D}$. Cancer staging were performed by specialist physicians. Venous blood samples were obtained and immediately processed to be used for the measurement of alpha-1 antitrypsin using commercially available radial immunodiffusion kit (Kent Laboratory Inc, Bellinham, Washigton) following manufacturer instructions. Alpha-1 AT blood levels were measured at two different time points, one before patients start their chemotherapy course and the other on the third week after chemotherapy course was started. A software package (Statistical Package for the Social Science, SPSS version 17) was used for calculations and statistical analysis. Statistical analysis was completed using paired t-test. A P-value of less than $0.05(\mathrm{P}<0.05)$ was considered statistically significant.

\section{Results}

Data obtained in this work demonstrated that $\alpha_{1}$-AT blood levels were significantly decreased on the third week after treatment with chemotherapy in all cancer patients included in this study except one patient with lung cancer. The summary of the obtained results are shown in the tables. Table- 1 shows that the mean difference (before - after) treatment for $\alpha_{1}$-AT blood levels is highly significant in lung and prostate cancer as indicated by $95 \%$ confidence interval (CI) and the $\mathrm{P}$-values. Table 2 and 3 are also demonstrate that the mean difference (before - after) treatment for $\alpha_{1}$-AT blood levels in lung and prostate cancer patients according to the stage of the disease is highly significant with the widening of the range of difference when we go toward more advanced stages.

Table 2. Mean Difference (Before - After) Treatment of Alpha-1 Antitrypsin Blood Levels in mg/dL in Lung Cancer Patients According to Stages

\begin{tabular}{lllll}
\hline Stages & I & II & III & IV \\
\hline Number of patients & 13 & 14 & 14 & 9 \\
Mean difference (before - after) treatment & 67.71 & 138.44 & 132.70 & 190.52 \\
SE (mean difference) & 13.78 & 15.36 & 13.90 & 17.23 \\
95\% CI of difference & $37.68,97.73$ & $105.25,171.63$ & $102.68,162.72$ & $150.79,230.25$ \\
P-value using paired (t) test & 0.000 & 0.000 & 0.000 & 0.000 \\
\hline
\end{tabular}

SE: Standard Error; Cl: Coefficient Interval. 
Table 3. Mean Difference (Before - After) Treatment of Alpha-1 Antitrypsin Blood Levels in mg/dL in Prostate Cancer Patients According to Stages

\begin{tabular}{lllll}
\hline Stages & A & B & C & D \\
\hline Number of patients & 11 & 13 & 12 & 14 \\
Mean difference (before - after) treatment & 75.93 & 119.91 & 148.93 & 191.24 \\
SE (mean difference) & 11.31 & 14.40 & 16.01 & 22.94 \\
95\% CI of difference & $50.73,101.13$ & $88.54,151.13$ & $113.71,184.16$ & $141.68,240.79$ \\
P-value using paired (t) test & 0.000 & 0.000 & 0.000 & 0.000 \\
\hline
\end{tabular}

SE: Standard Error; Cl: Coefficient Interval.

\section{Discussion}

Alpha-1 antitrypsin $\left(\alpha_{1}\right.$-AT) is a glycoprotein expressed and secreted by normal cells such as liver, macrophages, lung, gall bladder, pancreas and gastrointestinal tract. Moreover, it has also been demonstrated that $\alpha_{1}$-AT is expressed in malignant cells including lung, thyroid, pancreatic cancer and others [4-8, 18]. Studies have indicated that alpha-1 antitrypsin $\left(\alpha_{1}\right.$-AT) blood levels were significantly increased in a good number of malignant diseases [7-13]. In addition, it has been demonstrated that this increment in $\alpha_{1}$-AT blood levels is significantly correlated with cancer staging [8, 14-17]. In a previous study on lung and prostate cancer we demonstrated a direct and significant correlation between the elevated levels of the serum $\alpha_{1}$-AT and the stage of cancer [8]. Considering the above stated facts, we can suggest that the major source of the increased $\alpha_{1}$-AT blood levels in cancer patients is the growing cancer cells. In this work we measured $\alpha_{1}$-AT blood levels in untreated cancer patients before and three weeks after the treatment with chemotherapy. We demonstrated that these levels were significantly decreased at the third week after treatment. As indicated in the accompanied tables the mean difference (before - after) treatment is highly significant in both lung and prostate cancer. This difference is also significant between stages within the same type of cancer. Calculating the percentage of this decrease we found that the decrease in $\alpha_{1}$-AT blood levels is about $28.4 \%$ in lung cancer and about $28.9 \%$ in prostate cancer patients. The percentage of decrement in lung cancer patients was ranged from 5\% to $46 \%$ and from $11 \%$ to $57 \%$ in prostate cancer patients. When the percentages were calculated considering the cancer staging in both lung and prostate cancer patients the percentages of decrement were found to be higher in later stages compared with early stages and this mostly due to the fact that the starting $\alpha_{1}$-AT blood levels in late stages is much higher compared with early stages. Several reports have shown that high $\alpha_{1}$-AT blood levels in cancer cases are associated with cancer spreading and worse prognosis [4, 14, 15, 19-22]. Tahara et al demonstrated that the two-year survival rates, among one hundred twenty-six gastric carcinoma patients, clearly indicated that well-differentiated adenocarcinomas with $\alpha_{1}$-AT have worse prognosis than well-differentiated adenocarcinomas without $\alpha_{1}$-AT [20]. Higashiyama $M$ et al, in a clinical follow-up study of the patients with lung cancer, particularly in stage I, showed that strongly $\alpha_{1}$-AT -positive cases have poor prognosis than weak-to-moderately $\alpha_{1}$-AT -positive or $\alpha_{1}$-AT -negative cases. Therefore, they concluded that $\alpha_{1}$-AT expression status in tumor cells of lung adenocarcinoma may be a biological marker of prognostic significance in regard to tumor growth [4]. In addition, Karashima $\mathrm{S}$ et al suggested that alpha-1 AT in colorectal carcinoma is related to the invasive and metastatic capacity and thus it may serve as a biological marker for prognosis of colorectal carcinomas at relatively early stages [22]. In spite of a good number of publications concerning the relationship between $\alpha_{1}$-AT and tumor progression and poor prognosis, no special attention was given to this protein to be used for the evaluation of the outcome of cancer treatment. The only published work where it has been suggested that $\alpha_{1}$-AT serum levels might be used for the assessment of the efficacy of the treatment was by Konnova LA et al 1983 [23]. Our data came to confirm this suggestion and to strongly conclude that the measurement of $\alpha_{1}$-AT blood levels during the course of cancer treatment has a valuable clinical significance as indicator for the efficacy of treatment.

\section{References}

1. Gettins PG. Serpin structure, mechanism, and function. Chem Rev. 2002;102(12):4751-4804.

2. Carrell RW. alpha 1-Antitrypsin: molecular pathology, leukocytes, and tissue damage. J Clin Invest. 1986;78(6):1427-1431. 
3. Carrell RW, Jeppsson JO, Laurell CB, Brennan SO, Owen MC, Vaughan L, Boswell DR. Structure and variation of human alpha 1-antitrypsin. Nature. 1982;298(5872):329-334.

4. Higashiyama M, Doi O, Kodama K, Yokouchi H, Tateishi R. An evaluation of the prognostic significance of alpha-1-antitrypsin expression in adenocarcinomas of the lung: an immunohistochemical analysis. Br J Cancer. 1992;65(2):300-302.

5. Poblete MT, Nualart F, del Pozo M, Perez JA, Figueroa CD. Alpha 1-antitrypsin expression in human thyroid papillary carcinoma. Am J Surg Pathol. 1996;20(8):956963.

6. Yamaguchi N, Yamamura Y, Koyama K, Ohtsuji E, Imanishi J, Ashihara T. Characterization of new human pancreatic cancer cell lines which propagate in a protein-free chemically defined medium. Cancer Res. 1990;50(21):7008-7014.

7. El-Akawi ZJ, Al-Hindawi FK, Bashir NA. Alpha-1 antitrypsin (alpha1-AT) plasma levels in lung, prostate and breast cancer patients. Neuro Endocrinol Lett. 2008;29(4):482-484.

8. El-Akawi ZJ, Abu-Awad AM, Sharara AM, Khader Y. The importance of alpha-1 antitrypsin (alpha1-AT) and neopterin serum levels in the evaluation of non-small cell lung and prostate cancer patients. Neuro Endocrinol Lett. 2010;31(1):113-116.

9. Trachte AL, Suthers SE, Lerner MR, Hanas JS, Jupe ER, Sienko AE, Adesina AM, et al. Increased expression of alpha-1-antitrypsin, glutathione S-transferase pi and vascular endothelial growth factor in human pancreatic adenocarcinoma. Am J Surg. 2002;184(6):642-647; discussion 647-648.

10. Solakidi S, Dessypris A, Stathopoulos GP, Androulakis $\mathrm{G}$, Sekeris CE. Tumour-associated trypsin inhibitor, carcinoembryonic antigen and acute-phase reactant proteins CRP and alphal-antitrypsin in patients with gastrointestinal malignancies. Clin Biochem. 2004;37(1):56-60.

11. Hong WS, Hong SI. Clinical usefulness of alpha-1-antitrypsin in the diagnosis of hepatocellular carcinoma. J Korean Med Sci. 1991;6(3):206-213.

12. Bernacka K, Kuryliszyn-Moskal A, Sierakowski S. The levels of alpha 1-antitrypsin and alpha 1-antichymotrypsin in the sera of patients with gastrointestinal cancers during diagnosis. Cancer. 1988;62(6):1188-1193.
13. Tountas Y, Sparos L, Theodoropoulos C, Trichopoulos D. Alpha 1-antitrypsin and cancer of the pancreas. Digestion. 1985;31(1):37-40.

14. Li Y, Krowka MJ, Qi Y, Katzmann JA, Song Y, Mandrekar SJ, Yang P. Alpha1-antitrypsin deficiency carriers, serum alpha 1-antitrypsin concentration, and non-small cell lung cancer survival. J Thorac Oncol. 2011;6(2):291-295.

15. Millan J, Senra A, Lorenzo A, Romero J, Rodriguez P, Gallurt P. Biological changes in serum antiproteases as related to tumor progression. Tumour Biol. 1988;9(1):15-20.

16. Varela AS, Lopez Saez JJ. Utility of plasmatic levels of alpha-1-antiprotease (A1AP) as a cancer marker. Cancer Lett. 1995;89(1):15-21.

17. Thompson DK, Haddow JE, Smith DE, Ritchie RF. Elevated serum acute phase protein levels as predictors of disseminated breast cancer. Cancer. 1983;51(11):21002104.

18. Glasgow JE, Bagdasarian A, Colman RW. Functional alpha 1 protease inhibitor produced by a human hepatoma cell line. J Lab Clin Med. 1982;99(1):108-117.

19. Chang YH, Lee SH, Liao IC, Huang SH, Cheng HC, Liao PC. Secretomic analysis identifies alpha-1 antitrypsin (A1AT) as a required protein in cancer cell migration, invasion, and pericellular fibronectin assembly for facilitating lung colonization of lung adenocarcinoma cells. Mol Cell Proteomics. 2012;11(11):1320-1339.

20. Tahara E, Ito H, Taniyama K, Yokozaki H, Hata J. Alpha 1-antitrypsin, alpha 1-antichymotrypsin, and alpha 2-macroglobulin in human gastric carcinomas: a retrospective immunohistochemical study. Hum Pathol. 1984;15(10):957-964.

21. Ferrigno D, Buccheri G, Camilla T. Prognosis and lungcancer - the contribution of plasma-proteins. Oncol Rep. 1995;2(4):637-641.

22. Karashima S, Kataoka H, Itoh H, Maruyama R, Koono M. Prognostic significance of alpha-1-antitrypsin in early stage of colorectal carcinomas. Int J Cancer. 1990;45(2):244-250.

23. Konnova LA, Konnov BA, Mel'nikov LA, Zargarova OP. [Antiprotease activity of the blood serum of patients with the disseminated form of breast cancer before and after combined treatment]. Vopr Onkol. 1983;29(10):79. 